FEI-01-2020

\title{
TUBERÍAS RESISTENTES A LOS DESEQUILIBRIOS QUÍMICOS DEL AGUA. PVC ORIENTADO DURABILIDAD Y EFICIENCIA EN REDES DE TRANSPORTE EN DESALACIÓN. CASO CCRR. CUEVAS DEL ALMANZORA
}

\author{
$\underline{\text { Rincón, Marcos (1) (P) }}$ \\ Muñoz, Jorge (2)(P)
}

\author{
${ }^{1}$ Técnico Pre-Postventa, Molecor Tecnología, S.L., marcos.rincon@molecor.com \\ 2Jefe de Obra de obras hidráulicas, Talleres y Grúas Gonzalez S.L., \\ jorge@talleresygruasgonzalez.com
}

\section{Resumen}

La planta desaladora de la Comunidad de Regantes Cuevas de Almanzora, está ubicada en el levante almeriense, muy próxima a la línea de costa, en la pedanía de Palomares, junto a la rambla/desembocadura del río Almanzora.

La Instalación de Desalación de Aguas Salobres de Cuevas del Almanzora se construyó para dotar de agua de calidad a los socios de la Comunidad de Regantes de Cuevas del Almanzora convirtiendo recursos hídricos inservibles hasta ese momento en aptos para el riego.

La instalación de desalación cuenta con 7 pozos de extracción de agua salobre, un depósito de regulación, bombas de baja presión y de limpieza de filtros, filtros de sílice, microfiltros de cartuchos de 5 micras, bombas de alta presión de hasta 30 bar, 5 bastidores de $5000 \mathrm{~m}^{3} /$ día, equipo de limpieza química, bombas de impulsión a la red de Palomares de 100 m.c.a. y bombas de impulsión a la red de Cuevas del Almanzora de 180 m.c.a.

La solución adoptada es eficaz en la resolución de la problemática vigente en cuanto a dotar de suficiente garantía de abastecimiento y paliar el déficit actual en el regadío de la zona. Se analizaron para ello los aspectos técnicos, económicos y ambientales para adoptar la solución más viable que permitiera cumplir con dichos objetivos.

La tubería elegida para esta actuación debía ser resistente a las distintas salinidades del agua transportada. Gracias al diseño de la planta, el agua pura o desalinizada puede ser mezclada con agua de los pozos salinos, logrando así la salinidad requerida en cada momento por los regantes o usuarios. Es por ello, y por otras muchas ventajas relativas a su resistencia a la presión interna así como por sus propiedades mecánicas, por lo que finalmente se decidió optar por la instalación del PVC Orientado (PVC-O) en esta actuación.

\begin{abstract}
La desaladora de la Comunidad de Regantes Cuevas de Almanzora se construyó para dotar de agua de calidad a los socios de la Comunidad de Regantes de Cuevas del Almanzora convirtiendo recursos hídricos inservibles hasta ese momento en aptos para el riego. Se trata de una impulsión de aproximadamente $15 \mathrm{~km}$ que conecta la planta desaladora con una balsa
\end{abstract}


de acumulación desde la que riegan por gravedad gran parte de la zona regable. Se requiere de un sistema de distribución que permita trabajar tanto con aguas ácidas como alcalinas y la red de impulsión con Tuberías de PVC-O cumplía los requisitos del proyecto.

The Cuevas del Almanzora BrackishWater Desalination Facility was built to provide high quality water to members of the Cuevas de Almanzora Irrigation Community, by converting hitherto unusable water into water suitable for irrigation. The irrigation network, which has a length of approximately $15 \mathrm{~km}$, connects the desalination plant with the storage pond, from where a large part of the land is irrigated. The distribution system had to be capable of operating with both acidic and alkaline water and the irrigation network implemented, featuring PVC-O pipes, fulfilled all project requirements.

\section{1- Introducción}

La Instalación de Desalación de Aguas Salobres de Cuevas del Almanzora se construyó para dotar de agua de calidad a los socios de la Comunidad de Regantes de Cuevas del Almanzora añadiendo recursos hídricos, inservibles hasta ese momento, con una conductividad de entre 10.000 y $22.000 \mu \mathrm{S}$, dependiendo de la temporada, mezcla de sulfatos, carbonatos, etc.

El agua salobre del acuífero inferior de la cuenca del río Almanzora es tratada convirtiéndola en agua apta para riego y finalmente se impulsa a los embalses de la comunidad de regantes, ubicados a más de $15 \mathrm{~km}$ de distancia, para desde allí, ser distribuidos por gravedad.

La instalación de desalación cuenta con 7 pozos de extracción de agua salobre, un depósito de regulación, bombas de baja presión y de limpieza de filtros, filtros de sílice, micro filtros de cartuchos de 5 micras, bombas de alta presión de hasta 30 bar, 5 bastidores de $5000 \mathrm{~m}^{3} /$ día, equipo de limpieza química, bombas de impulsión a la red de Palomares de 100 m.c.a. y bombas de impulsión a la red de Cuevas del Almanzora de 180 m.c.a., además de todos los sistemas de gestión eléctrica y control, trafos de media y baja tensión, equipos de compensación de energía reactiva, autómata de control, etc.

La comunidad de regantes impone calidad mínima de producción de los bastidores pero normalmente requiere una conductividad de entre 1.000 y $1.500 \mu S$ en agua distribuida a la red. Esta producción es denominada como producción de agua a la carta debido a que la desaladora suministra la calidad de agua necesaria para compensar el defecto o exceso de conductividad de agua distribuida. De esta manera, si la calidad de otras aguas de aporte es mala se suministra agua pura para corregir a la baja la conductividad general, si por el contrario la Comunidad de Regantes se está dotando del sistema general de distribución de agua desalada de Acamad, necesita incrementar la conductividad general, lo que se corrige incrementando la salinidad de la mezcla impulsada hasta obtener el valor requerido.

Para poder producir de esta manera se requiere un sistema de distribución que permita trabajar tanto con aguas ácidas como alcalinas y la solución de la red de distribución, hasta el punto de mezcla, así lo permite.

La ejecución de la obra y su posterior explotación corrió a cargo de la UTE Sadyt-Talleres y Grúas González S.L. Sadyt, empresa de tratamiento de aguas perteneciente al Grupo Sacyr, siendo la mayor especialidad de Sadyt la desalación, tanto en diseño y construcción como en operación, lo que la convierte en una de las 10 mayores empresas del mundo en este sector. Sadyt tiene una probada experiencia en el suministro con éxito de grandes plantas por todo el mundo, con más de 1,6 millones de $\mathrm{m}^{3} /$ día instalados en plantas de ósmosis inversa y la 
mayor planta del mundo de Electrodiálisis reversible $\left(200.000 \mathrm{~m}^{3} / \mathrm{día}\right)$, en países como España, Israel, Australia, Argelia, Chile, Túnez, etc., y expansión por todo el mundo.

\section{2- Descripción de la actuación}

La planta está dividida en 4 módulos de producción independientes de $5.000 \mathrm{~m}^{3} /$ día más 2 de $2.500 \mathrm{~m}^{3} /$ día, pero cuenta con el aporte y la producción común. Recibe la energía a $20 \mathrm{kV}$ y dispone de 2 trafos de 2 MVA a $660 \mathrm{~V}$ y otro de servicios auxiliares de $630 \mathrm{kVA}$ a $380 \mathrm{~V}$.

\section{Bombeo de agua bruta desde pozos}

El agua salobre se extrae de una profundidad de $35 \mathrm{~m}$ y se acumula en el denominado depósito de agua bruta que actúa como regulador y da el tiempo de permanencia necesario para que actúen los químicos de pretratamiento en caso de que fuesen necesarios (Control de Cloro, $\mathrm{PH}$, turbidez, etc.).

\section{Filtración sobre sílex}

Del depósito de pretratamiento se bombea el agua, por medio de las bombas de baja presión, hasta los filtros horizontales de sílex, donde se eliminan los sólidos en suspensión existentes en el agua.

\section{Dosificaciones químicas (Reductor, Anti incrustante)}

A continuación de la filtración de sílex se aportan una serie de productos químicos que regulan la calidad del agua y permiten incrementar la conversión.

\section{Filtración de seguridad sobre cartuchos}

Con el fin de garantizar la total limpieza del agua se hace pasar el agua por la filtración de cartuchos que retiene impurezas de tamaño superior a 5 micras.

\section{Bombeo de alta presión}

Para alcanzar la presión necesaria para que se produzca el fenómeno de la ósmosis inversa se debe presurizar el agua por medio de la bomba de alta presión. En función de la salinidad del agua y por medio de un variador de frecuencia, se regulará la presión de trabajo.

\section{Líneas de producción de $5.000 \mathrm{~m}^{3} /$ día}

Una vez presurizada, el agua pasa a los denominados bastidores de osmosis inversa donde se hace pasar todo el caudal de agua a través de los tubos de membranas. Cada bastidor cuenta con 37 tubos en primera etapa y 17 en segunda y cada tubo cuenta con 6 membranas colocadas en serie. La primera etapa recibe el agua procedente de la bomba de alta presión, el $46 \%$ del agua pasa a través de la membrana como agua producto y el resto pasa a la siguiente etapa. Presurizando el agua de rechazo de primera etapa por medio de un recuperador de energía se alimenta la segunda etapa obteniendo de nuevo un $45 \%$ del agua con lo que se obtiene un total de un 70 a $72 \%$ del agua producto y un 28 a $30 \%$ de agua de rechazo que es vertida al mar por medio de un salmuero ducto hasta unos $600 \mathrm{~m}$ de la costa.

\section{Equipo de limpieza y desplazamiento}

Cada vez que se para la planta se debe realizar un desplazamiento del agua salobre existente dentro de los tubos de presión con agua pura. También se pueden realizar limpiezas químicas en caso de que se produzcan ensuciamientos por precipitación de sales, por crecimiento bacteriano u otros ensuciamientos.

Red de impulsión y distribución de $18 \mathrm{~km}$ con balsas de regulación 20.000 y $120.000 \mathrm{~m}^{3}$ El agua producto se almacena en un embalse construido a pie de planta desde donde se bombea a las diferentes redes de distribución. La comunidad de regantes demanda los 
caudales producidos por la planta con una calidad que variará en función de sus necesidades, de manera que en la aspiración del bombeo se mezcla el agua producto con parte de agua bruta filtrada hasta alcanzar la calidad solicitada. El agua es conducida por medio de la red de distribución hasta los embalses de distribución ubicados a 6 y $15 \mathrm{Km}$ hasta una cota de 150 m.c.a.

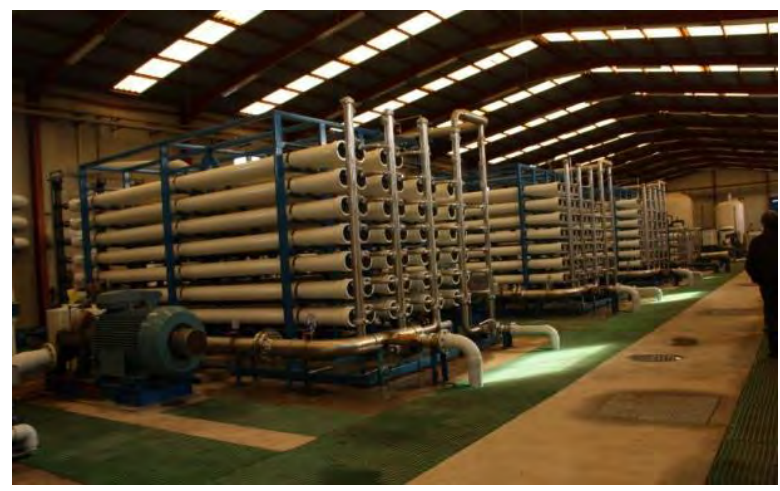

Figura 1. Planta impulsión.

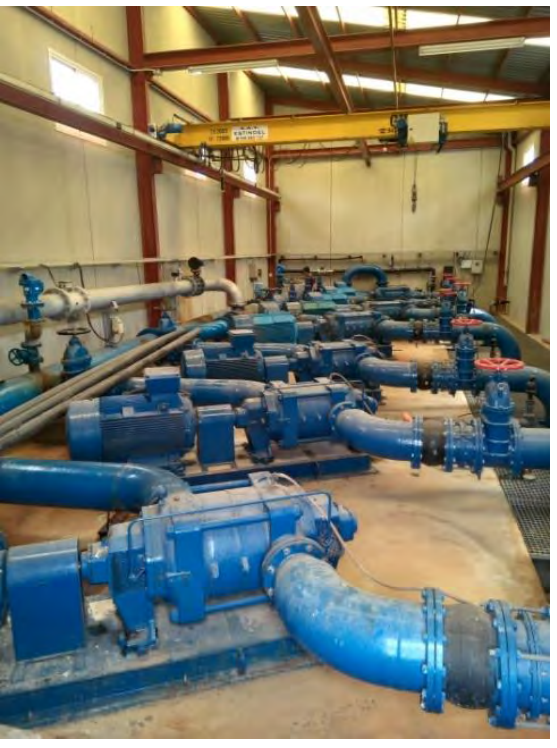

Figura 2. Planta de bombeo a balsa.

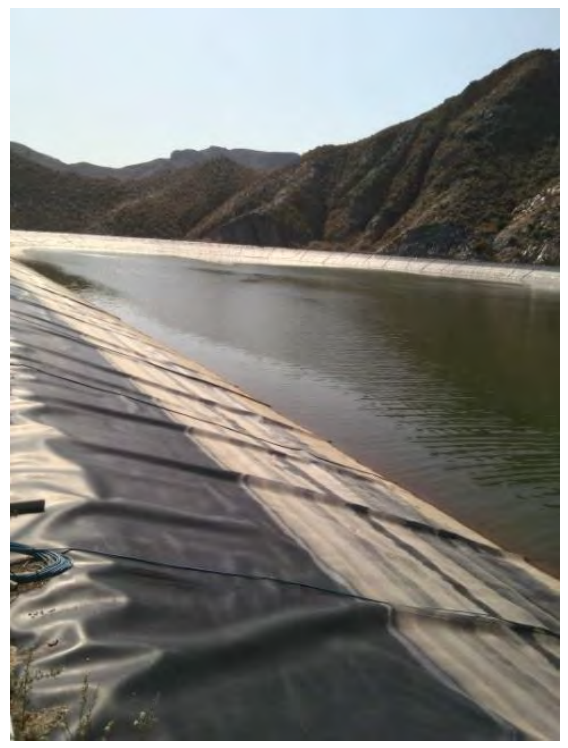

Figura 3. Balsa de acumulación.

\section{Sistema de control centralizado mediante SCADA}

En el control de todos los parámetros de funcionamiento, la gestión de históricos y alarmas, etc. se utiliza un sistema de control centralizado con un autómata programado. El carácter semiautomático del sistema reduce al mínimo la presencia de personal de operación permitiendo que el personal se dedique básicamente a mantenimiento y control.

\section{Turbocharger: Recuperador de energía}

El sistema de recuperación de energía instalado en plantas de Osmosis Inversa de dos etapas consiste en un equipo hidráulico turbina-bomba con eje solidario que aprovecha la presión de salida del rechazo de la planta para aumentar la presión entre etapas, aumentando la presión y la producción de la segunda etapa. 
El aporte de agua a la primera etapa se produce (p.e.) a 20 bar, el $46 \%$ del agua pasa a producto perdiendo la presión en el proceso, pero el $54 \%$ restante sale por el rechazo de la primera etapa con una pérdida de carga de unos 2 bar, o sea a 18 bar. Como se ha extraído agua pura, la concentración de sales del rechazo aumenta, lo que demanda una mayor presión para que se pueda producir el fenómeno de la Osmosis Inversa. Para aumentar esta presión se coloca un turbocharger entre etapas que eleva de 18 bar a 30 la entrada de la segunda etapa. En ésta el $45 \%$ del agua pasa a producto y el resto sale por el rechazo. De esta manera tenemos el $30 \%$ del agua de aporte a 28 bar que se inyectan en la parte de turbina del turbocharger pasando de 28 bar a 0 bar y en la parte bomba la presión pasa de 18 a 30 bar. Es un simple intercambio de energía con un rendimiento cercano al $80 \%$.

\section{3- Red de Impulsión}

\section{Red de impulsión y distribución de 15 km}

Se trata de una impulsión de aproximadamente $15 \mathrm{~km}$ que conecta la planta desaladora con una balsa de acumulación desde la que riegan por gravedad gran parte de la zona regable. La tubería discurre, desde la planta al embalse, por el cauce del propio río Almanzora, hasta abandonar dicho cauce a la altura del canal de remo, en dirección a la balsa de acumulación. Se optó por un diámetro $500 \mathrm{~mm}$ de diferentes timbrajes: PN25, PN20 bar y finalmente PN16 bar en el tramo final de conexión al depósito.

Tabla 1. Tubería $\mathrm{TOM}^{\circledR}$ de PVC-O instalada.

\begin{tabular}{|l|l|}
\hline Diámetro & $500 \mathrm{~mm}$ \\
\hline Timbraje & PN 25, PN20 y PN16 \\
\hline Caudal a derivar & $300 \mathrm{l} / \mathrm{s}$ \\
\hline Diferencia de cotas & $130,6 \mathrm{~m}$ \\
\hline Longitud de la conducción & $14.223,05 \mathrm{~m}$ \\
\hline Altura manométrica total & $206,84 \mathrm{~m}$ \\
\hline
\end{tabular}

El caudal impulsado es de $300 \mathrm{l} / \mathrm{s}$, la diferencia de cotas entre la planta y el embalse es de $130,6 \mathrm{~m}$ siendo la altura manométrica total de $206,84 \mathrm{~m}$.

Se requiere de un sistema de distribución que permita trabajar tanto con aguas ácidas como alcalinas. La tubería elegida para esta actuación debía ser resistente a la variabilidad de desequilibrios químicos del agua transportada. Gracias al diseño de la planta, el agua pura o desalinizada puede ser mezclada con agua de los pozos salinos, logrando así fluidos compatibles en cada momento con los requerimientos de los regantes o usuarios.

EI PVC Orientado es inmune a la corrosión y a las sustancias químicas presentes en la naturaleza. EI PVC Orientado es, por tanto, inerte a la degradación. Todo ello hace a la tubería especialmente indicada para la instalación de redes en terrenos agresivos, en presencia de corrientes vagabundas que aceleran la corrosión en otras tuberías tradicionales.

El proyecto original contempló esta actuación en poliéster (PRFV), pero los continuos problemas con este material en fase de explotación motivaron la decisión de sustituir este material por PVC Orientado (PVC-O). 


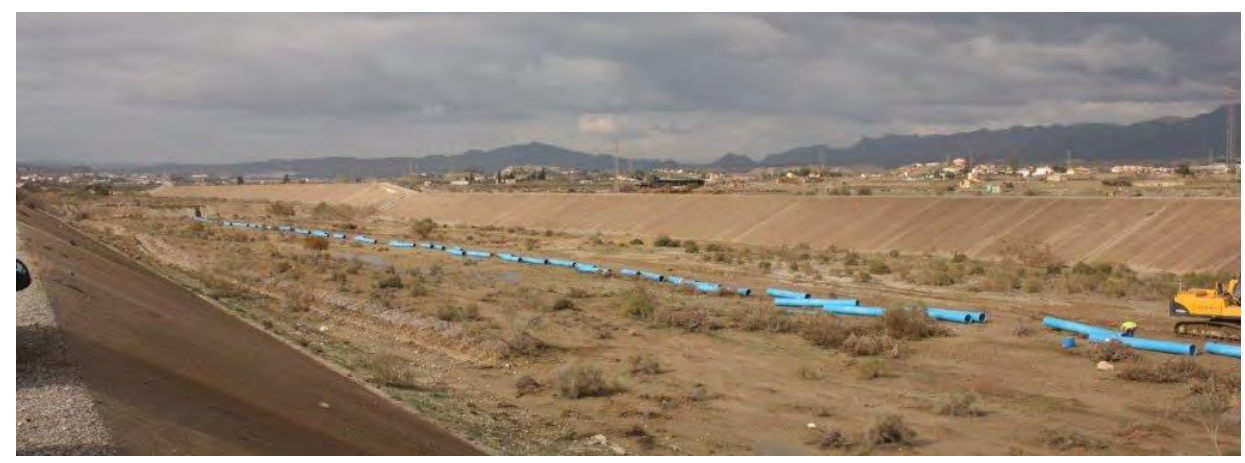

Figura 4. Tubería $\mathrm{TOM}^{\circledR}$ de PVC-O DN500 mm acopiada a lo largo de la traza.

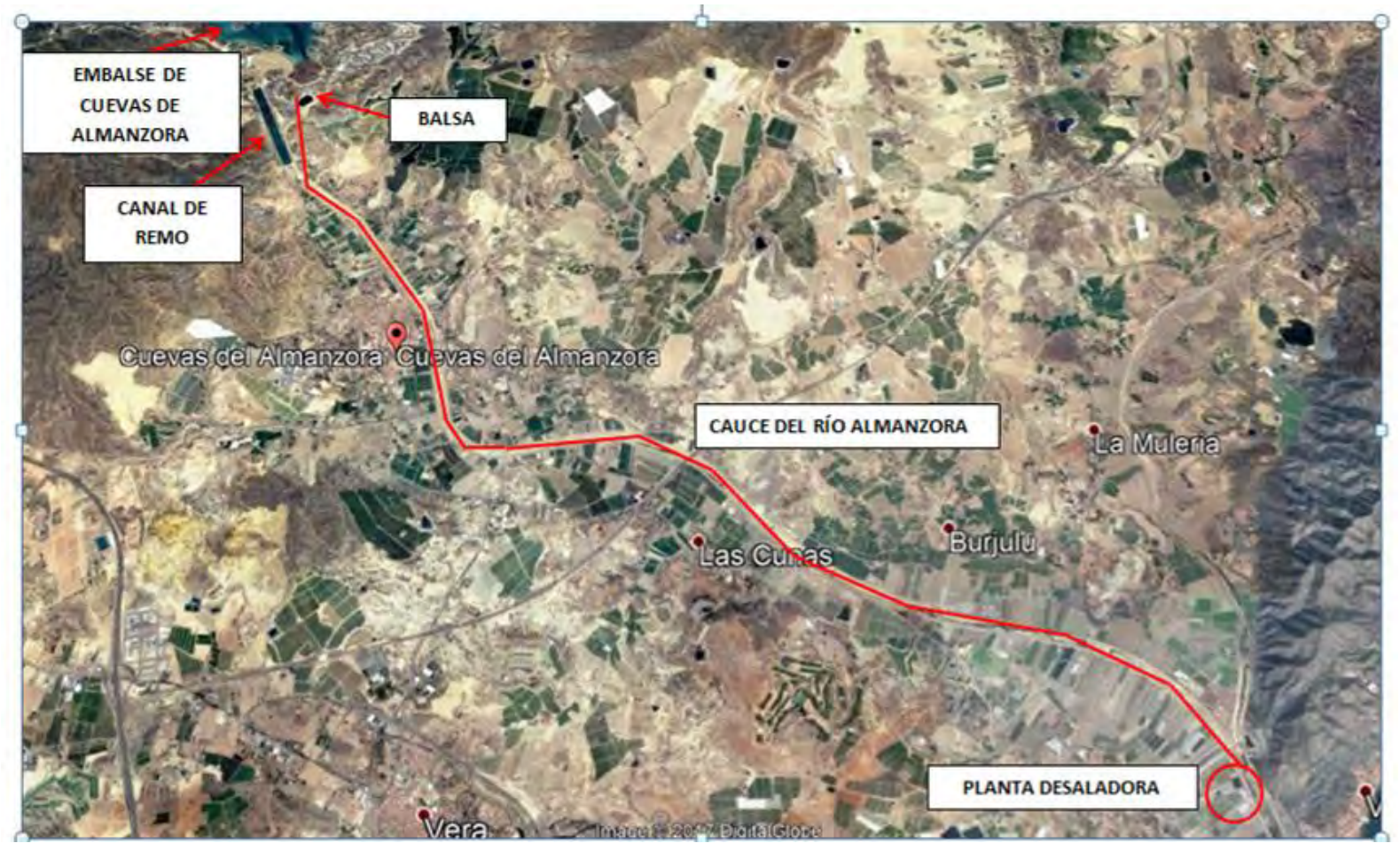

Figura 5. Plano del trazado de la impulsión

La opción del PVC Orientado (PVC-O) mejoraba los resultados hidráulicos de otros materiales (Velocidad-Pérdida de carga), como el PRFV, el acero o la fundición dúctil.

Tabla 2. Valores extraídos del Manual Técnico del Canal de Isabel II.

\begin{tabular}{lcccccc}
\hline \multicolumn{1}{c}{ Material } & Prandtl-Colebrook & \multicolumn{2}{c}{ Hazen-Willians } & \multicolumn{2}{c}{ Manning } \\
\hline & \multicolumn{2}{c}{ k/mm } & \multicolumn{3}{c}{ C } & \multicolumn{2}{c}{ N } \\
& nueva en servicio & nueva & en servicio & nueva & en servicio \\
\hline PVC-O & 0.003 & 0.060 & 150 & 140 & 0.007 & 0.009 \\
Fundición & 0.100 & 0.200 & 130 & 100 & 0.012 & 0.017 \\
Acero & 0.030 & 0.100 & 120 & 90 & 0.008 & 0.011 \\
Polietileno & 0.005 & 0.030 & 150 & 140 & 0.007 & 0.009 \\
PRFV & 0.030 & 0.060 & 110 & 100 & 0.009 & 0.010 \\
Hormigón & 0.300 & 3.000 & 140 & 110 & 0.013 & 0.017 \\
\hline
\end{tabular}


Así mismo, la baja celeridad del PVC-O reducía el valor de las sobrepresiones y depresiones originadas por paradas repentinas en la estación de bombeo.

Tabla 3. Valor de las celeridades de distintos materiales.

\begin{tabular}{lccc}
\hline & $E\left(\mathrm{~kg} / \mathrm{m}^{2}\right)$ & $e(\mathrm{~mm})$ & $a(\mathrm{~m} / \mathrm{s})$ \\
\hline Fundición (k9) & $170 \times 10^{8}$ & 9 & 1095 \\
Acero & $210 \times 10^{8}$ & 5 & 1011 \\
PRFV & $20 \times 10^{8}$ & 7 & 492 \\
PVC-U (PN16) & $3 \times 10^{8}$ & 29,7 & 424 \\
Polietileno (PN16) & $1 \times 10^{8}$ & 45,4 & 320 \\
TOM $^{\circledR}$ 500 PVC-O & $4 \times 10^{8}$ & 13 & 318 \\
\hline
\end{tabular}

EI PVC es esencialmente un polímero amorfo, en el que las moléculas se encuentran dispuestas en direcciones aleatorias. Sin embargo, bajo unas determinadas condiciones de presión, temperatura y velocidad, y mediante un estiramiento del material, es posible ordenar las moléculas del polímero en la misma dirección en la que se ha producido dicho estiramiento.

El proceso de Orientación Molecular mejora de forma espectacular las propiedades físicas y mecánicas del PVC, y le otorga unas características excepcionales, sin alterar las ventajas y propiedades químicas del polímero original. Se consigue así un plástico con unas insuperables cualidades de resistencia a la tracción y a la fatiga, flexibilidad y resistencia al impacto.

El proceso de fabricación de la tubería $\operatorname{TOM}^{\circledR}$ se realiza de forma continua y absolutamente automática, en lugar del tradicional sistema discontinuo, lo que proporciona un mayor control y regularidad al producto.

Los materiales pierden propiedades mecánicas al estar sometidos durante largo tiempo a esfuerzos. Esta característica definida como "fluencia" se manifiesta en mucho menor grado en el PVC-O 500, que en los plásticos convencionales, lo que conlleva unas mejores propiedades a largo plazo. Teniendo en cuenta que el PV C-O tiene una resistencia a la fatiga excepcional y una resistencia química excelente, podríamos hablar de una tubería capaz de soportar las presiones de trabajo durante más de 100 años. 


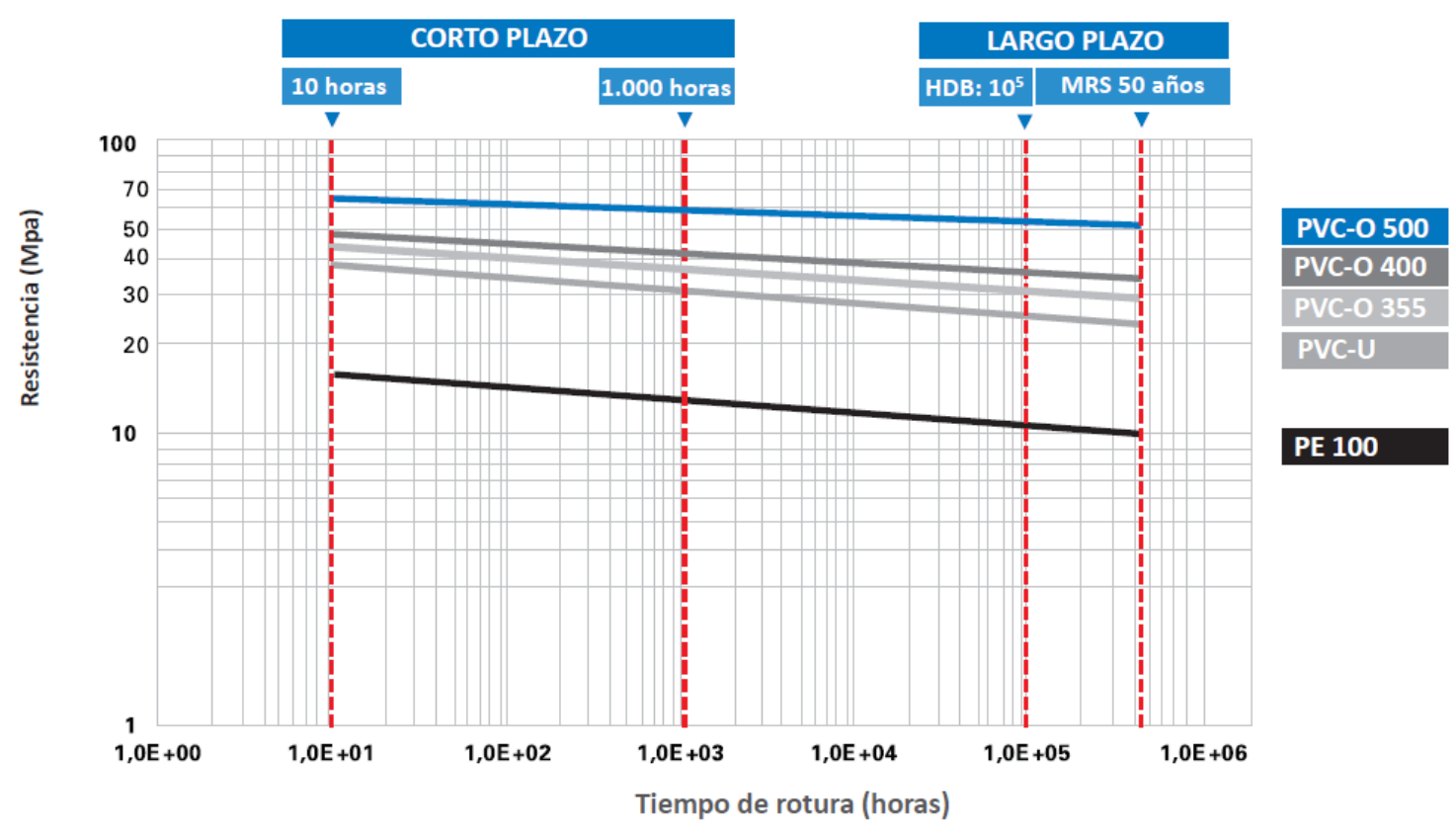

Figura 6. Curva de regresión de resistencia hidrostática del PVC-O TOM ${ }^{\circledR} 500$.

La norma UNE-ISO 16422:2015 (actualmente sustituida por la norma UNE-EN 17176:2019) contempla diferentes clases de material de PVC-O clasificados según su MRS (resistencia mínima requerida), debido a que la Orientación Molecular se puede lograr en mayor o menor medida dependiendo del proceso de fabricación.

La tubería $\mathrm{TOM}^{\circledR}$ de PVC-O se fabrica solamente según la clase más alta (PVC-O 500), ya que al ser la que tiene un grado de orientación más elevado es la que garantiza un mejor comportamiento mecánico. De esa forma, la tubería $\mathrm{TOM}^{\circledR}$ dispone en su mayor grado de las ventajas que el PVC-O presenta sobre otros materiales.

Tabla 4. Propiedades mecánicas.

\begin{tabular}{|c|c|c|c|c|}
\hline \multicolumn{5}{|c|}{ TUBERÍA TOM ${ }^{\circledR}$ PVC-O Clase 500} \\
\hline & PN12,5 & PN16 & PN20 & PN25 \\
\hline Clase de material & 500 & 500 & 500 & 500 \\
\hline MRS (MPa) & 50,0 & 50,0 & 50,0 & 50,0 \\
\hline Presión nominal (bar) & 12,5 & 16,0 & 20,0 & 25,0 \\
\hline Presión rotura a 50 años (bar) ${ }^{(1)}$ & 17,5 & 22,4 & 28,0 & 35,0 \\
\hline Presión rotura a 10 horas (bar) ${ }^{(1)}$ & 23,1 & 28,9 & 36,7 & 48,1 \\
\hline Presión de prueba máxima en obra (bar) ${ }^{(2)}$ & 17,5 & 21,0 & 25,0 & 30,0 \\
\hline Rigidez circunferencial $\left(\mathrm{kN} / \mathrm{m}^{2}\right)^{(3)}$ & 5 & 7 & 11 & 20 \\
\hline Color $^{(4)}$ & $\begin{array}{l}\text { azul/ } \\
\text { morado }\end{array}$ & $\begin{array}{c}\text { azul/ } \\
\text { morado }\end{array}$ & $\begin{array}{c}\text { azul/ } \\
\text { morado }\end{array}$ & $\begin{array}{c}\text { azul/ } \\
\text { morado }\end{array}$ \\
\hline
\end{tabular}

(1) A temperatura de $20^{\circ} \mathrm{C}$.

(2) Según norma UNE-EN 805:2000 con golpe de ariete estimado.

(3) Rigidez media en el tubo según tolerancias establecidas.

(4) Disponible en color azul (abastecimiento), morado (reutilización) y blanco (resistente a los rayos UV). Otros colores consultar.

La tubería $\mathrm{TOM}^{\circledR}$ presenta una gran resistencia ante los golpes. Se reducen así las roturas durante la instalación o las pruebas en obras producidas por caídas e impactos de piedras. 
Además, la Orientación Molecular impide la propagación de grietas y arañazos y elimina el riesgo de fisuras rápidas, gracias a la estructura laminar del tubo. El resultado es un espectacular aumento de la vida útil del producto.

Una de las propiedades del PVC-O que motivó su elección para esta obra fue su resistencia química. La tubería elegida debía ser resistente a las distintas salinidades del agua transportada. Gracias al diseño de la planta, el agua pura o desalinizada puede ser mezclada con agua de los pozos, logrando así la salinidad requerida en cada momento por los regantes o usuarios.

EI PVC Orientado es inmune a la corrosión y a las sustancias químicas presentes en la naturaleza. Además, no requiere ningún tipo de protección o recubrimiento especial, lo que repercute en un ahorro de costes.

La curva tensión-deformación del PVC-O cambia drásticamente respecto al comportamiento de los plásticos convencionales, resultando una curva característica de los metales. La transformación completa de las propiedades mecánicas del PVC-O respecto al PVC convencional solamente se logra en la clase más alta PVC-O 500, como es la de la tubería $\mathrm{TOM}^{\circledR}$.

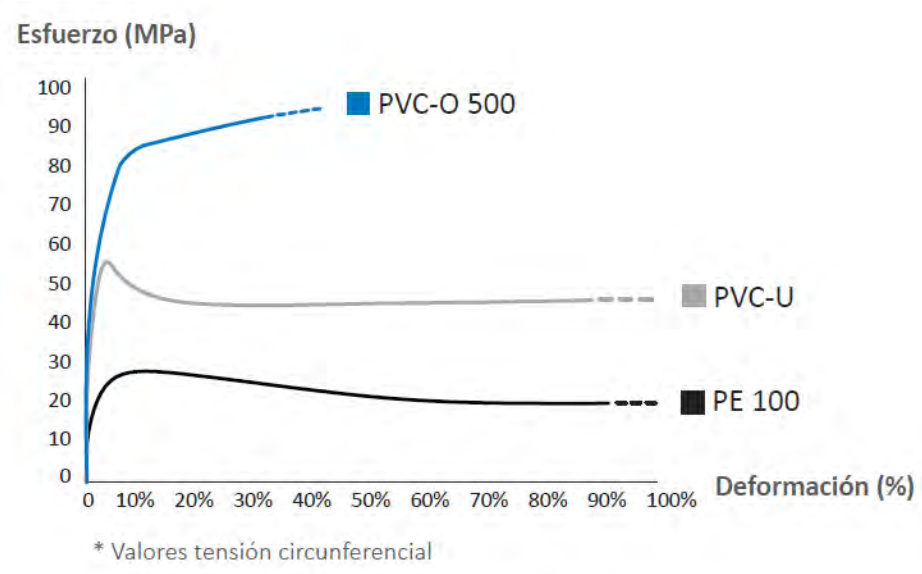

Figura 7. Curva de esfuerzo-deformación

El material de la excavación era un material aluvial, apropiado para el apoyo de la tubería y relleno de la zanja, se realizó el cribado del mismo para el tapado de la tubería, pero no se precisó de material de préstamo. Se trata de apoyar correctamente la totalidad de la longitud de la tubería, prestando especial atención a la zona de la copa. La única manera de lograr esto, es mediante el uso de materiales granulares en la base de la zanja, ya sean de la propia excavación o de préstamo.

La tubería no soportará ninguna carga de tráfico a lo largo de todo su trazado por lo que, tampoco se requirió compactación alguna en los rellenos.

El cribado del material de relleno se hizo mediante medios mecánicos. 

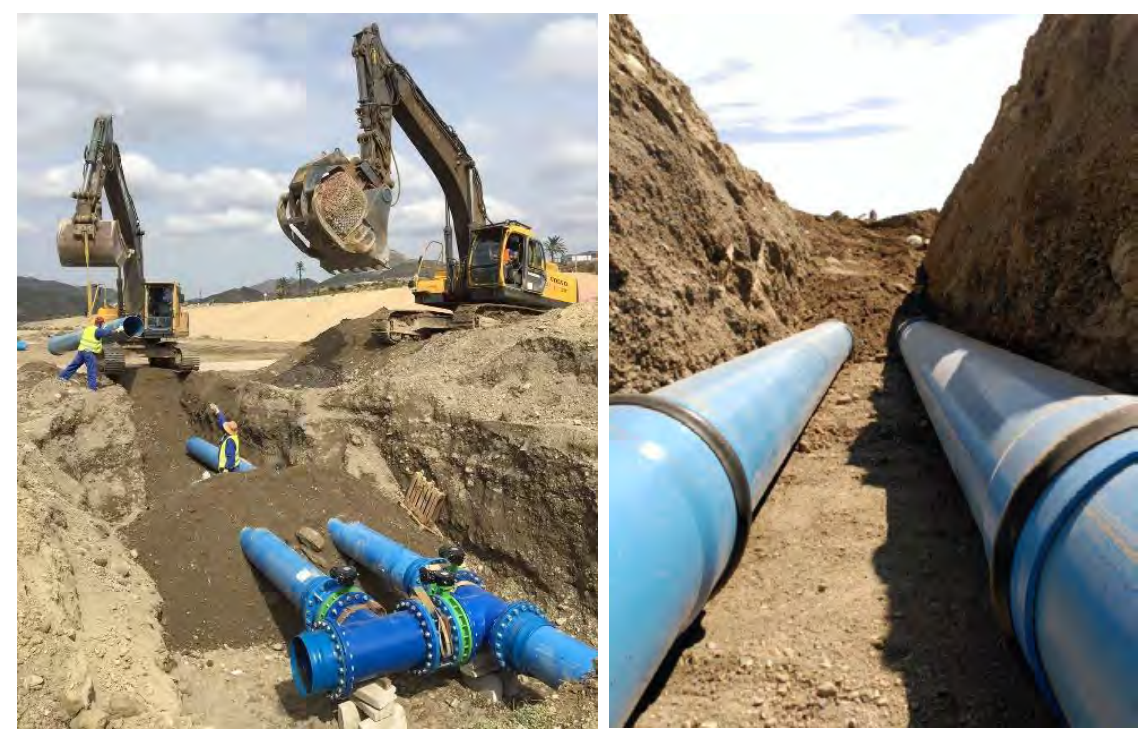

Figura 8. Detalle instalación Tubería $\mathrm{TOM}^{\circledR}$ de PVC-O DN500 mm

La instalación de la tubería se realizó mediante el uso de eslingas y la propia máquina retroexcavadora. Este modo de instalación permite el ensamblaje suave y correcto de las tuberías.

En las tuberías $\mathrm{TOM}^{\circledR}$ de Molecor, la estanqueidad del sistema se logra gracias a la junta. La junta está compuesta por un anillo de Polipropileno y un labio de caucho sintético que hacen que forme integral del tubo, impidiendo que se desplace o vuelque de su alojamiento o que sea arrollada en el montaje.

\section{4- Conclusiones}

EI PVC-O se consolida como la mejor solución ante los requerimientos técnicos de la propia explotación por diferentes motivos como:

- Se precisaba de una tubería con una excelente resistencia a los desequilibrios químicos del agua transportada.

- Se optó por un material con una baja celeridad, para minimizar las sobrepresiones producidas por paradas súbitas y no alcanzar valores muy altos. La baja celeridad del PVC-O reducía el valor de las sobrepresiones y depresiones originadas por paradas repentinas en la estación de bombeo.

- Ante los problemas sufridos con el material anteriormente instalado, se optó por un material fiable con una excelente durabilidad en el tiempo, dadas sus óptimas condiciones de diseño y resistencia hidrostática.

- Su excelente comportamiento mecánico frente a impactos, unido a su ligereza y fácil instalación, influyeron también notoriamente en la decisión del material a instalar.

En una zona en la que el agua está tan valorada, económica y culturalmente, se debe apostar por soluciones que minimicen las pérdidas de tan importante activo, ya no sólo a nivel de elección de tuberías.

Esta actuación, constituye un gran ejemplo, de cómo ante limitados recursos hídricos, el ser humano busca alternativas para sacar partido de la situación existente, en este caso a través de la desalación. 